\title{
High Efficiency Gene Transfer to Airways of Mice Using Influenza Hemagglutinin Pseudotyped Lentiviral Vectors
}

\author{
Manij Patel, Angela M. Giddings, John Sechelski, and John C. Olsen \\ Cystic Fibrosis/Pulmonary Research and Treatment Center, Department of Medicine University of \\ North Carolina at Chapel Hill, Chapel Hill NC 27599
}

\begin{abstract}
Background-A limitation to efficient lentivirus-mediated airway gene transfer is the lack of receptors to commonly used viral envelopes on the luminal surface of airway epithelia. The use of viral envelopes with natural tropism to the airway could be useful for overcoming this limitation.

Methods-We investigated influenza hemagglutinin (HA) pseudotyped EIAV-derived lentiviral vector-mediated gene transfer to the airway epithelium of adult and newborn mice. For these studies high-titer vectors were delivered by intranasal administration. In addition, we tested the feasibility of vector re-dosing to the nasal airway.
\end{abstract}

Results-Delivery of high-titer HA pseudotyped lentiviral vectors by nasal administration to newborn mouse pups or adult mice results in efficient transduction of airway epithelial cells in the nose, trachea, and lungs. In the nose vector expression was predominant in the respiratory epithelium and was not observed in the olfactory epithelium. In the trachea and large airways of the lung approximately $46 \%$ and $40 \%$, respectively, of surface epithelial cells could be transduced. The efficiency of re-dosing to the nasal airway of mice was found to be dependent upon the age of the animal when the first dose is administered and the length of time between doses.

Conclusions-A single intranasal dose of concentrated influenza HA-pseudotyped lentiviral vector is sufficient for efficient gene transfer to the airways of mice. This is a promising result that could lead to the development of effective gene transfer reagents for the treatment of cystic fibrosis and other human lung diseases.

\section{Keywords}

lentivirus; influenza virus; cystic fibrosis; gene delivery; viral vector

\section{Introduction}

Gene transfer has the potential to deliver therapeutic nucleic acids to epithelial cells of the airway for the treatment of cystic fibrosis (CF) and other lung diseases. Several studies have investigated the use of lentiviruses as gene transfer vehicles for the treatment of CF by

\footnotetext{
*Correspondence: JC Olsen, Cystic Fibrosis/Pulmonary Research and Treatment Center, CB\#7248, University of North Carolina, Chapel Hill, NC 27599, USA olyunc@ med.unc.edu Phone: 919-942-0549 Fax: 919-966-5178.

Disclosure: J.C.O. is a named inventor on patents involving EIAV-based gene transfer technology and has received royalties for use of EIAV-based vectors.
} 
delivery of a normal copy of the cystic fibrosis transmembrane conductance regulator (CFTR) cDNA to conducting regions of the airways [1-4]. Early studies demonstrated the lack of receptors on the apical surface of epithelial cells lining the lumen of the airways for viral vectors pseudotyped with the commonly used vesicular stomatitis virus (VSV)-G envelope [1,5-7]. Other studies have found that VSV-G pseudotyped vectors might be useful for gene transfer to fetal airways [8-11] or to long-lived alveolar macrophages residing in the lung $[12,13]$.

Recent work has focused on two approaches to increase the efficiency of lentiviral vector entry into epithelial cells lining the lumen of the conducting airways. In one approach, agents are used to transiently open up tight junctions to allow access of vectors pseudotyped with VSV-G to receptors on the basolateral membrane of polarized columnar epithelial cells or to basal cells $[4,14]$. While it will be important to fully assess the safety of this approach [15], this strategy may provide enhanced accessibility to adult airway stem/progenitor cells [4].

In a second approach, viral envelopes derived from viruses that are capable of using apical membrane receptors on polarized epithelial cells for attachment and entry have been used for pseudotyping lentiviral vectors. These include a modified viral envelope spike glycoprotein from Ebola virus [16], the GP64 envelope transmembrane protein from baculovirus [17, 18], and modified envelope proteins from sendai virus [3]. Although some of these studies have shown promise, efficient lentiviral vector gene transfer to the lung remains challenging. Efficient vector delivery is critical for a gene transfer approach for treating CF since it is believed that vector transduction of 5-10\% of the lung epithelium may be required for effective treatment $[19,20]$.

In previous work, we reported studies describing the pseudotyping of lentivirus vectors with the hemagglutinin (HA) envelope protein (subtype H7) from a highly pathogenic strain of avian influenza virus [21]. An important feature of using the HA envelope glycoprotein of influenza virus is that it initiates infection of polarized airway epithelial cells by binding sialic acid receptors on the apical membrane surface. Thus, lentiviral vectors pseudotyped with influenza HA can access the airway epithelium by delivery via the airway lumen. We found that production of vectors was greatly enhanced by co-expressing influenza neuraminidase (NA) glycoprotein and the influenza M2 ion channel protein [21]. Using cultures of well-differentiated mouse tracheal epithelial cells, delivery of HA-pseudotyped vectors to ciliated and non-ciliated cells was observed, with a marked preference for ciliated cells [21]. The preference for ciliated cells is advantageous, since those are thought to be important targets for the treatment of CF.

In this work, we report further improvements to this system that result in vector preparations with sufficient potency to efficiently deliver genes to the airways of adult and neonatal mice by intranasal administration. In addition, we explored the feasibility of re-dosing mice with the HA-pseudotyped vectors using luciferase imaging to quantify nasal gene expression following gene transfer. 


\section{Materials and Methods}

\section{Cell culture}

Human embryonic kidney 293T cells (a kind gift from Dr. Tal Kafri, University of North Carolina at Chapel Hill) were maintained in Dulbecco's modified Eagle's medium (DMEMH) (Sigma, St. Louis, MO) supplemented with 10\% fetal bovine serum (FBS) (Invitrogen, Carlsbad, CA). A clonal cell line that exhibited enhanced transfection efficiency and lentiviral vector production was isolated from parental 293T cells. These cells were further modified to express human $a_{v} \beta_{3}$ integrin to enhance attachment to tissue culture plates [22]. A clonal $a_{v} \beta_{3}$ integrin-expressing derivative was used for vector production. ED cells are normal equine dermal fibroblasts (American Type Culture Collection, CCL-57) and were cultured as described previously [23].

\section{Plasmid constructs}

The equine infectious anemia virus (EIAV)-based packaging plasmid, pEV53D, was derived from pEV53B [23] by removal of a NgoM IV fragment in the vector backbone containing a neomycin resistance gene. The LTR self-inactivating (SIN) EIAV gene transfer vector SIN6.1-CW [24] was modified by replacing the internal cytomegalovirus (CMV) enhancer/ promoter with a sequence containing the human CMV enhancer/chicken $\beta$-actin (CB) promoter. Reporter genes including nuclear-localized lacZ (nlacZ) from pHIT-CMV-nlacZ [25], firefly luciferase from the pGL3 basic plasmid (Stratagene, La Jolla, CA), or a dual nlacZ-luciferase expression cassette were cloned directly downstream of the internal CB promoter of SIN6.1-CBW. To construct the dual nlacZ-luciferase reporter, 18 amino acids from the FMDV 2A peptide encoding a stop-carry on translational recoding sequence [26] was inserted at the C-terminal Gln amino acid of nlac $Z$ and joined to the Glu amino acid at position 2 of luciferase. A linker sequence was placed at both ends of the $2 \mathrm{~A}$ sequence. The HIV-1-based packaging plasmid CMV $\Delta$ R8.74 [27] was obtained from Dr. Didier Trono (École Polytechnique Fédérale de Lausanne, Lausanne, Switzerland). The HIV-1 based gene transfer vector, LV-CB-nlac $Z$, was created by replacing the internal expression cassette in pTK642 [28] with the CB-nlacZ expression cassette in the EIAV-CB-nlacZ vector described above. The plasmid expressing the vesicular stomatitis virus (VSV) envelope glycoprotein, pCI-VSV-G, has been described previously [5]. The influenza virus M2 expression vector pCI-M2 was derived from pCB6-M2 [21] by subcloning the M2 cDNA sequence into the pCI vector (Promega Corporation, Madison WI). The pNAHA plasmid expression vector encoding influenza neuraminidase (NA) and influenza hemagglutinin (HA) was constructed by cloning a PCR amplified DNA fragment containing the influenza HA (subtype H7) cDNA from (A/FPV/Rostock/8/34) [29] into the SgrAI-XhoI site of multiple cloning site 2 and a PCR fragment containing the influenza NA (subtype N1) cDNA from A/Puerto Rico/ $8 / 34$ [21] into the MluI-AvrII site of multiple cloning site 1 of the pVITRO2 expression vector (InvivoGen, San Diego, CA). For expression of human influenza HA (subtype H3), PCR amplified DNA product encoding the HA cDNA from A/England/26/99 [30] was cloned into the MluI-AvrII site of the pVITRO2 expression vector. 


\section{Vector production and titering}

Recombinant EIAV-based lentiviral vector stocks were generated by transient transfection of 293T-based TAB22 cells as previously described [5]. Briefly, 1.93 $\times 10^{7}$ TAB22 cells were plated onto 15-cm tissue culture dishes containing DMEM-H medium with 10\% FBS $20 \mathrm{~h}$ prior to transfection. The next day, the medium was changed to $20 \mathrm{~mL}$ DMEM-H containing $6 \%$ FBS and each $15-\mathrm{cm}$ culture dish was transfected by the standard calcium phosphate method with $50 \mu \mathrm{g}$ gene transfer plasmid, $50 \mu \mathrm{g}$ pEV53D, $5 \mu \mathrm{g}$ pCI-M2, and $30 \mu \mathrm{g}$ pNAHA. After $24 \mathrm{~h}$ cultures were replenished with DMEM-H medium containing $2 \%$ FBS and 10 $\mathrm{mM}$ sodium butyrate and after a further $24 \mathrm{~h}$ incubation cell supernatant containing viral vectors was harvested. Virus preparations were clarified by low speed centrifugation (100 g, $10 \mathrm{~min}$ ) and filtered through $0.2 \mu \mathrm{m}$ PES membranes and used for transduction directly or subjected to high speed centrifugation at $5000 \mathrm{~g}$ (Beckman Avanti J-E centrifuge, JS-5.3 rotor) for $21 \mathrm{~h}$ at $8^{\circ} \mathrm{C}$. Virus pellets were suspended in vector formulation buffer $(5 \mathrm{mM}$ Hepes (pH 7.4), $37 \mathrm{mM} \mathrm{NaCl}$ and $40 \mathrm{mM}$ lactose) and stored at $-80^{\circ} \mathrm{C}$.

Recombinant lentiviral vector stocks were titered on $293 \mathrm{~T}$ cells. Cells were plated at $10^{5}$ cells/well in 12-well dishes $18 \mathrm{~h}$ prior to infection. Serial dilutions of viral vector stocks were applied to cells for $2 \mathrm{~h}$ before replenishing with fresh growth medium. For vectors encoding $l a c Z$, the percentage of transduced cells was determined using a hemocytometerbased assay as described previously [23]. For vectors encoding luciferase, a PCR assay was used to quantify vector proviral DNA in the chromosomal DNA of infected cells [31].

Briefly, after infection, cells were passaged twice and washed extensively with PBS to make sure all contaminating plasmid DNA was removed. Genomic DNA from these cells was harvested with the DNeasy Kit (Qiagen Corporation, Valencia, CA). The number of integrated vector copies was determined by Light-Cycler PCR using the FastStart DNA Master SYBR Green kit (Roche, Indianapolis, IN) and primers for a region of the WPRE sequence: 5'-CGCTGCTTTAATGCCTTTGT-3' and 5'-ACAACACCACGGAATTGTCA' 3 . The results were compared to a standard from cells infected with a known copy number of vector and the infectious units (IU)/ml of the original vector stock was determined.

\section{In vivo delivery of lentiviral vectors to mice and luciferase imaging}

All procedures using animals were approved by the Institutional Animal Care and Use Committee of the University of North Carolina at Chapel Hill, and were conducted in accordance with policies for the ethical treatment of animals established by the National Institutes of Health.

For lentiviral vector administration to newborn (1-2 day old) mice, the vector $(6 \mu \mathrm{L})$ was administered drop-wise to the left nostril of isoflurane-anesthetized CD1 mice (Charles River Laboratories, Wilmington, MA). Similarly, isoflurane-anesthetized 4-week-old young adult CD1 or BALB/c mice (Charles River Laboratories, Wilmington, MA) were dosed intranasally with a $20-40 \mu \mathrm{L}$ volume of vector. Isoflurane anesthesia $(2.5 \%$ isoflurane $/ 1.5 \mathrm{~L}$ oxygen per minute) and dosing of animals was carried out in a vented biological safety cabinet. For live animal imaging of nasal luciferase expression, mice were anesthetized with isoflurane and D-luciferin (Gold Biotechnology, St. Louis, MO) substrate ( $20 \mu \mathrm{L}$ of 25 $\mathrm{mg} / \mathrm{mL}$ D-luciferin in PBS) was delivered by intranasal administration [32]. Mice were 
imaged using the IVIS Lumina optical imaging system (Caliper Life Sciences, Hopkinton, MA) and images of luciferase activity were collected using a CCD camera interfaced to a computer.

\section{X-Gal histochemistry}

For processing of mouse lungs for X-Gal staining of cryosections, lungs were inflated through the trachea with OCT embedding as described previously [33] and frozen tissue was sectioned at $10 \mu \mathrm{m}$. Sections were fixed with $0.5 \%$ glutaraldehyde in PBS, washed with PBS, and stained for $4 \mathrm{~h}$ at $37^{\circ} \mathrm{C}$ with X-Gal Solution ( $1 \mathrm{mg} / \mathrm{mL} \mathrm{X-Gal} \mathrm{in} \mathrm{PBS} \mathrm{(pH} \mathrm{7.0)}$ containing $20 \mathrm{mM}$ potassium ferricyanide, $20 \mathrm{mM}$ potassium ferrocyanide, and $1 \mathrm{mM}$ $\mathrm{MgCl}_{2}$ ). For X-Gal staining of intact tissue, lungs were inflated with and submerged in $0.5 \%$ glutaraldehyde for $2 \mathrm{~h}$ at $4{ }^{\circ} \mathrm{C}$, washed in PBS/ $1 \mathrm{mM} \mathrm{MgCl} 2$, and stained in X-Gal Solution for $16 \mathrm{~h}$ as described [33]. Tissues were washed in water and embedded in paraffin for preparation of $8 \mu \mathrm{m}$ sections. For analysis of nlac $Z$ expression in the nasal cavity, heads were processed for $\mathrm{X}$-Gal staining and decalcification prior to sectioning as described [6].

\section{Neutralization of vector infectivity by mouse sera}

Blood was drawn from CD-1 mice before each vector instillation and then again when the mice were sacrificed. Serum samples were heat inactivated for $30 \mathrm{~min}$ at $56^{\circ} \mathrm{C}$ to destroy complement. To test for neutralization of infectivity, serial two-fold dilutions of sera from initial 1:4 dilutions were incubated with approximately 20,000 RLU of pseudotyped EIAVCMV-luciferase vectors for $1 \mathrm{~h}$ at $37^{\circ} \mathrm{C}$ and inoculated in triplicate onto ED cells seeded the previous day in 96-well plates at $10^{4}$ cells per well [34]. Cells were assayed $72 \mathrm{~h}$ postinfection for luciferase activity using the SteadyGlo substrate (Promega Corporation, Madison WI) and the signal was read with a Veritas plate-reader luminometer (Turner Biosystems, Sunnyvale, CA).

\section{Results}

\section{Production of influenza HA pseudotyped lentiviral vectors}

Previously, we reported that optimal production of influenza virus HA (subtype H7) pseudotyped lentiviral vectors based on equine infectious anemia virus (EIAV) or HIV-1 required co-expression of influenza neuraminidase (NA) and influenza M2 proteins [21]. In order to simplify vector production, cDNAs for the expression of HA and NA were coexpressed from a single plasmid thus reducing the number of plasmids required for transient production from five to four (Figure 1). The reduction in the number of plasmids resulted in approximately a 3-fold increase in vector production, such that non-concentrated vector preparations with titers up to $10^{6}$ infectious units $/ \mathrm{mL}$ could be obtained. Vector production of HA-pseudotyped EIAV-CB-nlacZ could be scaled up to $1000 \mathrm{~mL}$ without loss in expected yield. Following collection of the culture supernatant, vector preparations were concentrated up to 3000 -fold resulting in concentrated vector stocks with titers up to about $10^{9}$ infectious units $/ \mathrm{mL}$ (average titer $=7.5 \times 10^{8} \mathrm{IU} / \mathrm{ml}$, range $=2.6 \times 10^{8}-1.4 \times 10^{9} \mathrm{IU} / \mathrm{mL} ; \mathrm{n}=7$ ). 


\section{Transduction of mouse airways by nasal delivery of HA-pseudotyped lentiviral vectors}

To evaluate vector expression following delivery to mouse airways, a single administration of HA-pseudotyped EIAV-CB- $n L a c Z\left(2 \times 10^{7} \mathrm{IU}\right.$, unless indicated otherwise $)$ was delivered in a volume of $30 \mu \mathrm{L}$ to 4 -week-old $\mathrm{CD}-1$ mice by intranasal inhalation. Animals were sacrificed three weeks after gene transfer and the airways were processed for staining with $\mathrm{X}$-Gal for detection of $ß$-galactosidase activity expressed from the nuclear-localized lac $Z$ reporter gene (nlacZ). In some experiments, intact glutaraldehyde-fixed tissues were stained directly. In other experiments, cryosections of lungs and trachea were fixed and stained with $\mathrm{X}-\mathrm{Gal}$.

To locate EIAV-CB- $n L a c Z$ expression in the nasal passage, the nasal cavity was fixed, stained with X-Gal and de-calcified. Coronal sections were prepared and sampled for microscopic examination. Expression of $n l a c Z$ was detected in surface epithelial cells of the nasal airway (Figure 2). Nasal lac Z expression was commonly found in ciliated cells in the respiratory epithelium lining the ventral region of the nasal septum, although expression could be observed elsewhere in the nasal cavity (Figure 2A,C). In contrast, lac Z expression was absent in surface sustentacular cells and olfactory sensory neurons of the olfactory epithelium from the dorsal region of the nasal septum (Figure 2B). These results suggest a specificity of this HA-pseudotyped lentivirus vector for expression in nasal respiratory epithelium.

Because the respiratory epithelium in the nasopharynx is useful for differentiating the bioelectric properties between CF mice and non-CF mice [35], more distal sections of the nasal passage were examined for nlacZ expression. As shown in Figure 2D, significant EIAV-CB-nlacZ expression could be observed in nasopharyngeal epithelia. Thus, the nasopharynx is a potential target for assessing the normalization of bioelectric activity in CF mice by treatment with HA-pseudotyped vectors encoding CFTR cDNA

\section{Lentiviral vector gene expression in adult trachea and tracheal submucosal glands}

$\mathrm{X}$-Gal stained cryosections of the trachea readily revealed EIAV-CB- $n L a c Z$ expression (Figure 3B,D) in surface epithelium. No appreciable X-Gal staining was detected in shaminfected control mice (Figure 3A,C). To estimate the efficiency of gene transfer, the percentage of $\mathrm{X}$-Gal stained cells on the surface of the tracheal epithelium was determined by comparing the number of X-Gal stained cells to total surface cells in X-Gal stained cryosections. It was found that $45.7 \% \pm 6.3 \%$ (mean $\pm S E M, n=4)$ of the surface epithelial cells were transduced.

In the proximal trachea, expression was also observed in submucosal glands below the airway surface (Figure 3E,F). While the percentage of transduced gland cells was estimated to be at least 10-fold lower than tracheal surface expression, submucosal gland expression of $n l a c Z$ was not rare. From a screen of mice in the experiment described in Figure 3, submucosal gland expression was observed in four of four CD1 mice and three of four $\mathrm{BALB} / \mathrm{c}$ mice. 


\section{Lentiviral vector gene expression in adult mouse lung}

Evidence of X-Gal staining was evident in whole lungs of mice dosed with the EIAV-CB$n L a c Z$ vector (Figure 4B-D) but not in sham-infected control mice (Figure 4A). Staining could be observed throughout the airways including distal regions of branching airway extending to terminal bronchioles (Figure 4D). In cross sections of dissected mouse lungs, $\mathrm{X}$-Gal stained cells could be detected in small and large airways of all five mouse lobes (Figure 5A-E). Higher magnification of X-Gal stained cryosections confirmed that expression was localized to surface cells in the lung epithelium (Figure 6A,B). In contrast, there was no comparable $\mathrm{X}$-Gal staining in lungs from negative control mice (Figure $5 \mathrm{~F}$ and Figure 6D). To estimate the efficiency of gene transfer, the percentage of X-Gal stained cells in the large airways was determined in ten 300-400 $\mu \mathrm{m}$ representative segments from stained cryosections. It was found that $40.3 \% \pm 11.9 \%$ (mean \pm SEM, $n=4$ ) of the surface epithelial cells were transduced in large airways.

To determine if other lentivirus-based vectors could be used for efficient gene transfer to the lung, we tested a HIV-1-based vector encoding an analogous CB-nlacZ expression cassette. It was found that nasal delivery of $20 \mu \mathrm{L}\left(2 \times 10^{7} \mathrm{IU}\right)$ of the HA pseudotyped HIV-1 based nlac $Z$ vector could also efficiently transduce the lung epithelium of CD1 mice (Figure 6C). Thus, the HA pseudotyping system that is described in this report may also be useful for gene transfer to mouse airways by non-EIAV-based lentiviral vectors.

\section{Delivery of influenza HA-pseudotyped lentivirus vectors to neonatal mouse airways}

Because pathogenesis of CF lung disease may become apparent shortly after birth [36], we tested the ability of HA-pseudotyped EIAV lentiviral vectors to transfer genes to neonatal mouse airways. Vectors were delivered by dropwise instillation into the left nostril of isoflurane-anesthetized neonates (1-2 days old). Because the volume that could be instilled safely to newborn mice was limited, a preliminary pilot experiment established that a $6 \mu \mathrm{L}$ delivery volume was well tolerated by mouse pups. Sequential (up to three) $6 \mu \mathrm{L}$ doses could be given to newborns provided that mice were allowed to wake and recover from anesthesia between each dose. In these experiments, a dual nlacZ-luciferase expression vector was used, in which expression of nlac $Z$ and firefly luciferase were linked by a viral 2 A "stop-carry on" peptide sequence [26]. At various times after the mice were dosed with the vector, luciferin was instilled intranasally and luciferase activity was measured (Figure $7 \mathrm{~A})$. In parallel control experiments, the same lot of vector $(20 \mu \mathrm{L})$ was delivered to 4 -weekold mice. Luminescence from luciferase activity was detected at the earliest time point, $72 \mathrm{~h}$ after transduction, in both neonatal and adult mice (Figure 7B). The magnitude of nasal luciferase expression in neonatal compared to adult mice was similar, suggesting that host factors required for transduction by this HA-pseudotyped vector are in place in both age groups. With adult mice, nasal gene expression following a single dose of $20 \mu \mathrm{L}$ was half maximal at day 3 , reaching a plateau in expression by day 7 . In contrast, nasal gene expression in neonatal mice reached a plateau by day 3 (Figure 7B).

\section{Lentiviral vector lacZ expression in neonatal mouse nose and lung}

The use of a dual nlacZ-luciferase expression cassette allowed for histochemical analysis of $n l a c Z$ gene expression in the nose and more distal airways. Following the 10-day luciferase 
measurement (Figure 7B), neonatal mice were euthanized and frozen sections of lungs were fixed and stained with X-Gal. Sections were also prepared from nasal airways from X-Gal stained and de-calcified heads. Nasal expression was observed mainly on the epithelial surface of the nasal septum, although expression could also be observed in other regions of the nasal epithelium (Figure 7C,D). Similar to adult mice, the lung epithelium of neonatal mice showed wide spread X-Gal staining (Figure 7E). As assessed by image analysis, no significant difference in nasal luciferase gene expression was noted for the three doses (6, 12, and $18 \mu \mathrm{L}$ ) that were administered to neonates Figure 7B). This contrasted to measurements made in the lung where there appeared to be a dose-response relationship between vector dose and the relative number of cells transduced in the airway epithelium (Figure 7F). At the highest dose (18 $\mu \mathrm{L})$, approximately $18 \%(\mathrm{n}=2)$ of the epithelial surface of the large airway in the left lobe of neonatal mice was transduced with the HApseudotyped EIAV-CB-nlacZ-luciferase vector.

From these studies we conclude that nasal vector gene expression can be detected within three days following gene transfer to 1-2 day old neonates and it is possible to obtain efficient delivery to the lungs of neonatal mouse airways by intranasal inhalation.

\section{Effect of vector re-administration to mice nasal airway}

For treatment of many genetic diseases using a gene transfer approach, it will be important to re-administer the vector if expression of the vector wanes due to cell turnover or other mechanisms. A possible complication of re-administering lentiviral vectors to adult animals with a mature immune system could be limited gene transfer by the second dose due to the generation of a neutralizing antibody response against the vector following the first dose. By contrast, if the first dose is given to a neonate whose developing immune system is still immature, it is possible that the efficiency of the second dose would be similar to the efficiency of dosing a naïve animal [37]. We performed a series of experiments with CD-1 mice to determine if the host immune response against HA-pseudotyped lentiviral vectors would prevent or tolerate a subsequent administration of a second dose of vector containing the same pseudotype.

In an initial experiment, 4 week old mice were dosed with $2.4 \times 10^{7}$ IU influenza HA pseudotyped EIAV-CB-nlacZ by nasal inhalation. Either three weeks or three months later, these mice or parallel naive mice were challenged by nasal administration with $7 \times 10^{6} \mathrm{IU}$ EIAV-CB-luciferase pseudotyped with HA of the same H7 subtype. Note that the challenge vector contained a different transgene than the vector administered in the first dose, as we wanted to eliminate the effect of pre-existing immunity against transgene expression. The kinetic profile of nasal luciferase expression is shown in Figure 8. Mice previously dosed with vector and re-dosed at three weeks with EIAV-CB-luciferase had 10-20\% of the expression levels of control mice receiving a single dose of vector (Figure 8A). In contrast, when the time period between doses was increased from 3 weeks to three months, mice receiving two doses had $30-40 \%$ of the expression levels compared to control mice that received a single dose (Figure $8 \mathrm{~B}$ ). These results suggest that there is a decrease in gene transfer efficiency upon re-administration of vectors with the same HA envelope pseudotype, however, the host response resulting in lowered gene transfer efficiency wanes with time. 
This experiment was repeated, except that the initial dose of HA pseudotyped EIAV-CB-lac Z was administered to 1-2 day old newborn mice. The mice were then challenged either 3 weeks (Figure 8C) or 12 weeks later (Figure 8D) with HA pseudotyped EIAV-CB-luciferase. In neither case was there a decline in gene expression efficiency compared to control naïve mice.

\section{Detection of a serum neutralizing response in treated adult mice}

In the experiments involving re-dosing of adult mice (Figure 8A, B), it was not clear if reduced gene transfer efficiency was due to an adaptive immune response to the vector or due to other mechanisms. To ascertain whether neutralizing antibodies had been generated in 4 week old mice administered with the first vector, sera were collected and tested in a vector neutralization assay. The results in Figure 9A indicate that sera from mice dosed with HA pseudotyped EIAV vectors effectively inhibited gene transfer of HA pseudotyped vectors with the same $\mathrm{H} 7$ subtype in a neutralization assay. The calculated anti-H7 HA IC90 serum titer (serum dilution that yields the inhibitory concentration required for $90 \%$ inhibition) for Mouse 1 was found to be 85, while Mouse 2 had an IC90 of 14. A commercial polyclonal antibody specific for $\mathrm{H} 7 \mathrm{HA}$ influenza virus was used as a positive control and had a strong neutralizing activity in this assay. Pre-immune sera or sera from non-transduced littermates did not show neutralizing activity.

To determine the specificity of the neutralizing response, sera from mice dosed with the $\mathrm{H} 7$ HA pseudotype or a commercial anti-H7 antiserum were tested for their ability to inhibit transduction by a lentiviral vector pseudotyped with HA from a different serological influenza subtype, H3. As shown in Figure 9B, the commercial H7 HA anti-serum or sera from mice dosed with $\mathrm{H} 7 \mathrm{HA}$ EIAV vectors were not effective at inhibiting infectivity of an EIAV vector with a human influenza H3 HA pseudotype. In addition, VSV-G pseudotyped vectors were also not inhibited by sera from animals dosed with H7 HA pseudotyped EIAV vectors (unpublished data). These results are consistent with the generation of a specific immune response in mice dosed with $\mathrm{H} 7 \mathrm{HA}$ pseudotyped EIAV vectors. These results also suggest that the HA is the major neutralizing determinant of HA pseudotyped EIAV vectors since it was the only variable in the production of the two different influenza HA pseudotypes. All other vector proteins, including the influenza neuraminidase (NA) and M2 proteins were common to the production of both $\mathrm{H} 7$ and $\mathrm{H} 3$ pseudotypes.

\section{Discussion}

Pseudotyping lentiviruses with influenza virus HA is challenging in that the functions of influenza virus NA and influenza M2 may be required for optimal vector production. We found that co-expressing NA and HA from the same plasmid led to more efficient vector production than we described previously [21] enabling the preparation of concentrated vector preparations with titers approaching $10^{9} \mathrm{IU} / \mathrm{ml}$.

A single dose of concentrated influenza HA-pseudotyped EIAV-based lentiviral vectors delivered by nasal administration to mice could efficiently transduce the respiratory epithelium of the nose, trachea, and all five lobes of the mouse lung. The efficiency of gene transfer to the lung (18\%, neonates, $40 \%$ adults) was in excess of the $5-10 \%$ threshold 
thought to be important to provide benefit in a treatment strategy for CF lung disease [19, 20]. Thus, if this vector system could be adapted for treatment of human CF, it is possible that a lentivirus-based approach could be used to effectively treat aspects of this lung disease. While it is generally accepted that innate barriers including mucus, the glycocalyx and other components in the airway lumen have evolved to prevent invasion by microorganisms, the results of the studies reported here are consistent with the hypothesis that exploiting the features of relatively successful respiratory viruses can be used to generate effective gene transfer vectors that can overcome innate barriers for efficient lung gene transfer.

In the nasal epithelium of mice, transduction by the HA pseudotyped EIAV-CB-nlac $Z$ vector appeared to be limited to respiratory epithelium. Transduction of significant olfactory epithelium in the nose was not observed. Respiratory epithelium of the nasopharynx was also transduced, which might prove to be useful in assays to assess the normalization of bioelectric properties in CF mice by lentiviral vectors encoding CFTR cDNA [35].

While a previous study has shown that tracheal submucosal glands can be transduced by vectors following intratracheal injection [38], the data reported in this study suggests that nasal delivery can also lead to transduction of submucosal glands, albeit at a lower rate than the surface epithelium. Because ciliated epithelial cells within submucosal glands express CFTR and are thought to be an important target for treatment of cystic fibrosis [39], it is possible that the ability of influenza HA pseudotypes to target these cells could be exploited in treatment strategies.

The treatment of CF using a gene transfer approach requires expression of CFTR over the lifetime of the patient. While previous studies using lentivirus-based gene transfer vector have shown long-term nasal gene expression $[3,4,17,18]$, we considered that normal cell turnover might require repeat vector administration. A possible complication of vector readministration could be limited gene transfer due to the generation of a neutralizing immune response against the vector. We found that application of a second dose of HA-pseudotyped vectors is feasible, with the efficiency of gene transfer of the second dose dependent upon the age of mice receiving the first dose and the time interval between doses. Previous lentivirus-based gene transfer studies using other viral envelope pseudotypes, including a baculovirus GP64 pseudotyped feline immunodeficiency virus vector [40] and a sendai F/HN pseudotyped simian immunodeficiency virus based vector [3] have also shown the feasibility of repeat dosing of the nasal airway of mice using the same vector pseudotype.

Because we used a HA from an avian influenza virus (A/Fowl Plague Virus/Rostock/8/34) that has not adapted to replicate in human cells, it is likely that further modification of the HA pseudotyping system would be beneficial in order to obtain optimal gene transfer efficiency to human airways for treatment of cystic fibrosis. The avian influenza HA used here is known to bind preferentially to terminal sialic acids attached with $a-(2,3)$ linkages. Adaptation of avian influenza virus to replicate in the upper human respiratory tract commonly includes changes in the sialic acid receptor binding domain of HA to recognize sialic acids attached with $a-(2,6)$ linkages that are abundant in the human airway [41-43]. Thus, the use of HA from human influenza virus strains or the modification of avian 
influenza virus HA to utilize sialic acid receptors common in the human respiratory tract [44-47] may be required to optimize the efficiency of influenza HA pseudotyped lentivirusbased vector delivery for human clinical studies.

\section{Acknowledgments}

We are grateful to Kimberlie Burns and Donald Joyner of the UNC CF Center Histology Core for tissue embedding and sectioning, Michael Chua and Neal Kramarcy of the UNC Michael Hooker Microscopy Core for helpful discussions and equipment access, and to Wanda O'Neal of the UNC CF Center Molecular Core for equipment access. This work was supported by research grants from the Cystic Fibrosis Foundation (RDP RO26, subproject 5) and a Molecular Therapy Core Center Grant from NIH/NIDK (P30 DK065988, subproject 9). Research Support was also provided by Oxford BioMedica Ltd to J.C.O. We are grateful to Dr. Tal Kafri, Dr. Raymond J. Pickles, and Dr. Wendy S. Barclay for providing reagents.

\section{References}

1. Goldman MJ, Lee PS, Yang JS, et al. Lentiviral vectors for gene therapy of cystic fibrosis. Hum Gene Ther. 1997; 8:2261-2268. [PubMed: 9449379]

2. Limberis M, Anson DS, Fuller M, et al. Recovery of airway cystic fibrosis transmembrane conductance regulator function in mice with cystic fibrosis after single-dose lentivirus-mediated gene transfer. Hum Gene Ther. 2002; 13:1961-1970. [PubMed: 12427306]

3. Mitomo K, Griesenbach U, Inoue M, et al. Toward gene therapy for cystic fibrosis using a lentivirus pseudotyped with Sendai virus envelopes. Mol Ther. 2010; 18:1173-1182. [PubMed: 20332767]

4. Stocker AG, Kremer KL, Koldej R, et al. Single-dose lentiviral gene transfer for lifetime airway gene expression. J Gene Med. 2009; 11:861-867. [PubMed: 19634193]

5. Johnson LG, Mewshaw JP, Ni H, et al. Effect of host modification and age on airway epithelial gene transfer mediated by a murine leukemia virus-derived vector. J Virol. 1998; 72:8861-8872. [PubMed: 9765431]

6. Johnson LG, Olsen JC, Naldini L, et al. Pseudotyped human lentiviral vector-mediated gene transfer to airway epithelia in vivo. Gene Ther. 2000; 7:568-574. [PubMed: 10819571]

7. Wang G, Slepushkin V, Zabner J, et al. Feline immunodeficiency virus vectors persistently transduce nondividing airway epithelia and correct the cystic fibrosis defect. J Clin Invest. 1999; 104:R55-62. [PubMed: 10587528]

8. Tarantal AF, Lee CI, Ekert JE, et al. Lentiviral vector gene transfer into fetal rhesus monkeys (Macaca mulatta): lung-targeting approaches. Molecular therapy : the journal of the American Society of Gene Therapy. 2001; 4:614-621. DOI: 10.1006/mthe.2001.0497. [PubMed: 11735346]

9. Tarantal AF, McDonald RJ, Jimenez DF, et al. Intrapulmonary and intramyocardial gene transfer in rhesus monkeys (Macaca mulatta): safety and efficiency of HIV-1-derived lentiviral vectors for fetal gene delivery. Mol Ther. 2005; 12:87-98. [PubMed: 15963924]

10. Toelen J, Deroose CM, Gijsbers R, et al. Fetal gene transfer with lentiviral vectors: long-term in vivo follow-up evaluation in a rat model. Am J Obstet Gynecol. 2007; 196:352, e351-356. [PubMed: 17403419]

11. Yu ZY, McKay K, van Asperen P, et al. Lentivirus vector-mediated gene transfer to the developing bronchiolar airway epithelium in the fetal lamb. J Gene Med. 2007; 9:429-439. [PubMed: 17410609]

12. Wilson AA, Murphy GJ, Hamakawa H, et al. Amelioration of emphysema in mice through lentiviral transduction of long-lived pulmonary alveolar macrophages. The Journal of clinical investigation. 2010; 120:379-389. DOI: 10.1172/JCI36666. [PubMed: 20038801]

13. Hirayama S, Sato M, Liu M, et al. Local long-term expression of lentivirally delivered IL-10 in the lung attenuates obliteration of intrapulmonary allograft airways. Human gene therapy. 2011; 22:1453-1460. DOI: 10.1089/hum.2010.225. [PubMed: 21568692]

14. Kremer KL, Dunning KR, Parsons DW, et al. Gene delivery to airway epithelial cells in vivo: a direct comparison of apical and basolateral transduction strategies using pseudotyped lentivirus vectors. J Gene Med. 2007; 9:362-368. [PubMed: 17380490] 
15. Johnson LG, Vanhook MK, Coyne CB, et al. Safety and efficiency of modulating paracellular permeability to enhance airway epithelial gene transfer in vivo. Hum Gene Ther. 2003; 14:729747. [PubMed: 12804137]

16. Medina MF, Kobinger GP, Rux J, et al. Lentiviral vectors pseudotyped with minimal filovirus envelopes increased gene transfer in murine lung. Mol Ther. 2003; 8:777-789. [PubMed: 14599811]

17. Sinn PL, Burnight ER, Hickey MA, et al. Persistent gene expression in mouse nasal epithelia following feline immunodeficiency virus-based vector gene transfer. J Virol. 2005; 79:1281812827. [PubMed: 16188984]

18. Buckley SM, Howe SJ, Sheard V, et al. Lentiviral transduction of the murine lung provides efficient pseudotype and developmental stage-dependent cell-specific transgene expression. Gene Ther. 2008; 15:1167-1175. [PubMed: 18432275]

19. Johnson LG, Olsen JC, Sarkadi B, et al. Efficiency of gene transfer for restoration of normal airway epithelial function in cystic fibrosis. Nature Genetics. 1992; 2:21-25. [PubMed: 1284642]

20. Dorin JR, Farley R, Webb S, et al. A demonstration using mouse models that successful gene therapy for cystic fibrosis requires only partial gene correction. Gene therapy. 1996; 3:797-801. [PubMed: 8875228]

21. McKay T, Patel M, Pickles RJ, et al. Influenza M2 envelope protein augments avian influenza hemagglutinin pseudotyping of lentiviral vectors. Gene Ther. 2006; 13:715-724. [PubMed: 16397505]

22. Olsen, JC., Patel, M., Wilcox, DA. Methods and Compositions for Enhancing Cell Adhesion Properties.. 2011. United States PatentUS 007939326B2

23. Olsen JC. Gene transfer vectors derived from equine infectious anemia virus. Gene Ther. 1998; 5:1481-1487. [PubMed: 9930301]

24. O'Rourke JP, Hiraragi H, Urban K, et al. Analysis of gene transfer and expression in skeletal muscle using enhanced EIAV lentivirus vectors. Mol Ther. 2003; 7:632-639. [PubMed: 12718906]

25. Wilcox DA, Olsen JC, Ishizawa L, et al. Integrin alphaIIb promoter-targeted expression of gene products in megakaryocytes derived from retrovirus-transduced human hematopoietic cells. Proc Natl Acad Sci U S A. 1999; 96:9654-9659. [PubMed: 10449749]

26. Donnelly ML, Luke G, Mehrotra A, et al. Analysis of the aphthovirus 2A/2B polyprotein 'cleavage' mechanism indicates not a proteolytic reaction, but a novel translational effect: a putative ribosomal 'skip'. The Journal of general virology. 2001; 82:1013-1025. [PubMed: 11297676]

27. Dull T, Zufferey R, Kelly M, et al. A third-generation lentivirus vector with a conditional packaging system. J Virol. 1998; 72:8463-8471. [PubMed: 9765382]

28. Titus MA, Zeithaml B, Kantor B, et al. Dominant-negative androgen receptor inhibition of intracrine androgen-dependent growth of castration-recurrent prostate cancer. PLoS One. 2012; 7:e30192. DOI: 10.1371/journal.pone.0030192. [PubMed: 22272301]

29. Hatziioannou T, Valsesia-Wittmann S, Russell SJ, et al. Incorporation of fowl plague virus hemagglutinin into murine leukemia virus particles and analysis of the infectivity of the pseudotyped retroviruses. J Virol. 1998; 72:5313-5317. [PubMed: 9573311]

30. Owen RE, Yamada E, Thompson CI, et al. Alterations in receptor binding properties of recent human influenza H3N2 viruses are associated with reduced natural killer cell lysis of infected cells. J Virol. 2007; 81:11170-11178. [PubMed: 17670834]

31. Sastry L, Johnson T, Hobson MJ, et al. Titering lentiviral vectors: comparison of DNA, RNA and marker expression methods. Gene Ther. 2002; 9:1155-1162. [PubMed: 12170379]

32. Buckley SM, Howe SJ, Rahim AA, et al. Luciferin detection after intranasal vector delivery is improved by intranasal rather than intraperitoneal luciferin administration. Hum Gene Ther. 2008; 19:1050-1056. [PubMed: 18847316]

33. Bell P, Limberis M, Gao G, et al. An optimized protocol for detection of E. coli beta-galactosidase in lung tissue following gene transfer. Histochem Cell Biol. 2005; 124:77-85. [PubMed: 15947941] 
34. Tallmadge RL, Brindley MA, Salmans J, et al. Development and characterization of an equine infectious anemia virus Env-pseudotyped reporter virus. Clin Vaccine Immunol. 2008; 15:11381140. [PubMed: 18448619]

35. Grubb BR, Rogers TD, Boucher RC, et al. Ion transport across CF and normal murine olfactory and ciliated epithelium. American journal of physiology Cell physiology. 2009; 296:C1301-1309. DOI: 10.1152/ajpcell.00578.2008. [PubMed: 19321738]

36. Ramsey BW, Banks-Schlegel S, Accurso FJ, et al. Future directions in early cystic fibrosis lung disease research: an NHLBI workshop report. American journal of respiratory and critical care medicine. 2012; 185:887-892. DOI: 10.1164/rccm.201111-2068WS. [PubMed: 22312017]

37. Mbawuike IN, Six HR, Cate TR, et al. Vaccination with inactivated influenza A virus during pregnancy protects neonatal mice against lethal challenge by influenza A viruses representing three subtypes. Journal of virology. 1990; 64:1370-1374. [PubMed: 2304146]

38. Kobinger GP, Weiner DJ, Yu QC, et al. Filovirus-pseudotyped lentiviral vector can efficiently and stably transduce airway epithelia in vivo. Nat Biotechnol. 2001; 19:225-230. [PubMed: 11231554]

39. Engelhardt JF, Yankaskas JR, Ernst SA, et al. Submucosal glands are the predominant site of CFTR expression in the human bronchus. Nature Genetics. 1992; 2:240-248. DOI: 10.1038/ ng1192-240. [PubMed: 1285365]

40. Sinn PL, Arias AC, Brogden KA, et al. Lentivirus vector can be readministered to nasal epithelia without blocking immune responses. J Virol. 2008; 82:10684-10692. [PubMed: 18768988]

41. Matrosovich MN, Matrosovich TY, Gray T, et al. Human and avian influenza viruses target different cell types in cultures of human airway epithelium. Proc Natl Acad Sci U S A. 2004; 101:4620-4624. [PubMed: 15070767]

42. Tumpey TM, Maines TR, Van Hoeven N, et al. A two-amino acid change in the hemagglutinin of the 1918 influenza virus abolishes transmission. Science. 2007; 315:655-659. DOI: 10.1126/ science.1136212. [PubMed: 17272724]

43. Pappas C, Viswanathan K, Chandrasekaran A, et al. Receptor specificity and transmission of H2N2 subtype viruses isolated from the pandemic of 1957. PLoS One. 2010; 5:e11158. DOI: 10.1371/ journal.pone.0011158. [PubMed: 20574518]

44. Bateman AC, Busch MG, Karasin AI, et al. Amino acid 226 in the hemagglutinin of H4N6 influenza virus determines binding affinity for alpha2,6-linked sialic acid and infectivity levels in primary swine and human respiratory epithelial cells. Journal of virology. 2008; 82:8204-8209. DOI: 10.1128/JVI.00718-08. [PubMed: 18550676]

45. Song H, Wan H, Araya Y, et al. Partial direct contact transmission in ferrets of a mallard H7N3 influenza virus with typical avian-like receptor specificity. Virology journal. 2009; 6:126. DOI: 10.1186/1743-422X-6-126. [PubMed: 19682381]

46. Herfst S, Schrauwen EJ, Linster M, et al. Airborne transmission of influenza A/H5N1 virus between ferrets. Science. 2012; 336:1534-1541. DOI: 10.1126/science.1213362. [PubMed: 22723413]

47. Imai M, Watanabe T, Hatta M, et al. Experimental adaptation of an influenza H5 HA confers respiratory droplet transmission to a reassortant $\mathrm{H} 5 \mathrm{HA} / \mathrm{H} 1 \mathrm{~N} 1$ virus in ferrets. Nature. 2012; 486:420-428. DOI: 10.1038/nature10831. [PubMed: 22722205] 

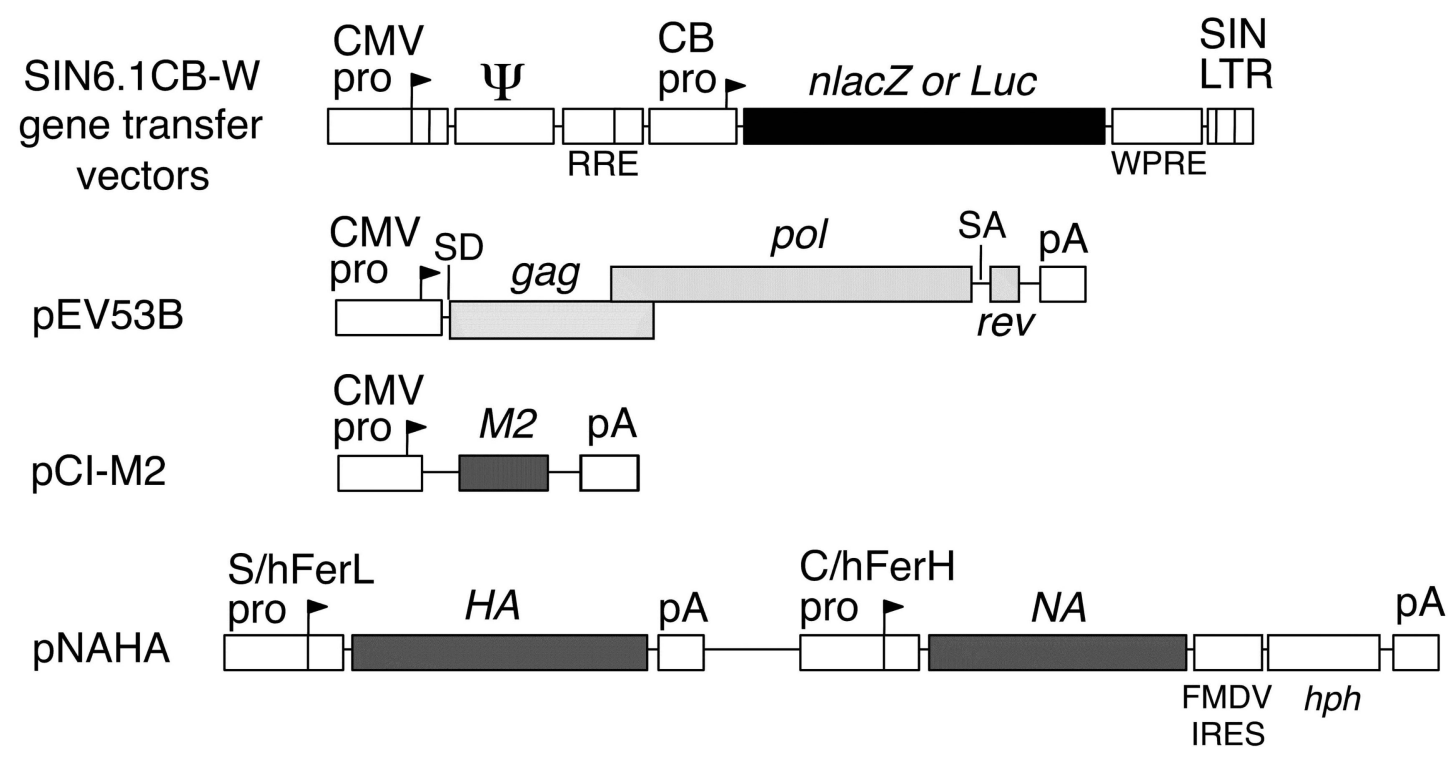

Figure 1.

Plasmid constructs for pseudotyping lentiviral vectors with influenza virus envelope proteins. The EIAV SIN6.1CB-W gene transfer vector contains a CMV enhancer/promoter fused to the R and U5 domains of the EIAV long terminal repeat (LTR) sequence, the viral Rev Responsive Element (RRE), RNA encapsidation sequence ( $\Psi$ ), an internal hybrid CMV enhancer/chicken $\beta$-actin promoter driving the nuclear-localized E. coli ß-galactosidase (nlacZ) or firefly luciferase ( $L u c$ ) genes, the woodchuck hepatitis virus post-transcriptional regulatory element (WPRE), and a 3' self-inactivating (SIN) LTR sequence. The gag-pol-rev expression vector (pEV53B) is used to express the EIAV Gag, Pol, and Rev proteins. 5' and 3' splice sites are indicated (SD and SA). The pCI-M2 vector is used to express the influenza virus $\mathrm{M} 2$ ion channel. The pNAHA vector is used for expression of influenza virus neuraminidase (NA) and influenza virus hemagglutinin (HA) genes. The plasmid backbones are not shown. Other abbreviations: S/hFerL, hybrid SV40 enhancer/human ferritin light chain promoter; $\mathrm{C} / \mathrm{hFerH}$, hybrid $\mathrm{CMV}$ enhancer/human ferritin heavy chain promoter; FMDV IRES, Foot and mouth disease virus internal ribosome entry site sequence; $h p h$, hygromycin B phosphotransferase gene; $\mathrm{pA}$, polyadenylation signal. 

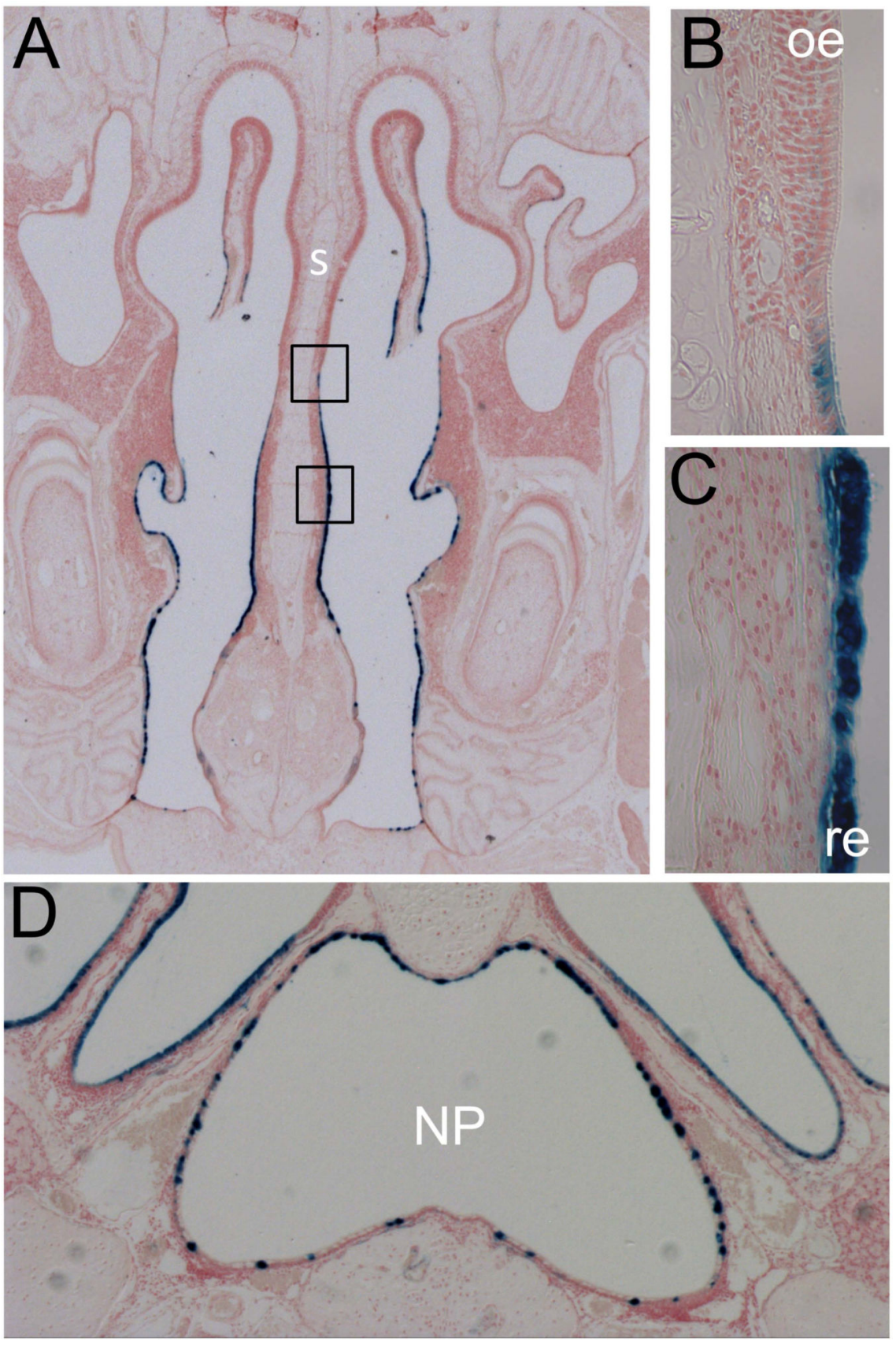

Figure 2.

Expression of influenza HA pseudotyped EIAV-CB-nlacZ vector in nasal cavity of adult mice. Three weeks following vector nasal administration to the right nostril of four week old mice, mice were analyzed for expression of nlacZ. (A) Coronal section from X-Gal stained nasal cavity. Vector nlacZ expression appears as blue staining. $\mathrm{S}$ denotes the nasal septum. The upper and lower boxed regions of the nasal septum were magnified (x20) and shown in panels (B) and (C), respectively. (B) The transition zone between the olfactory epithelium (oe) and respiratory epithelium along the nasal septum. (C) Region of respiratory epithelium (re) from the nasal septum, which is efficiently transduced by HA pseudotyped lentiviral 
vectors. (D) Section from distal nasal airway showing EIAV-CB-nlacZ expression in nasopharyngeal epithelium. NP, nasopharyngeal cavity. 

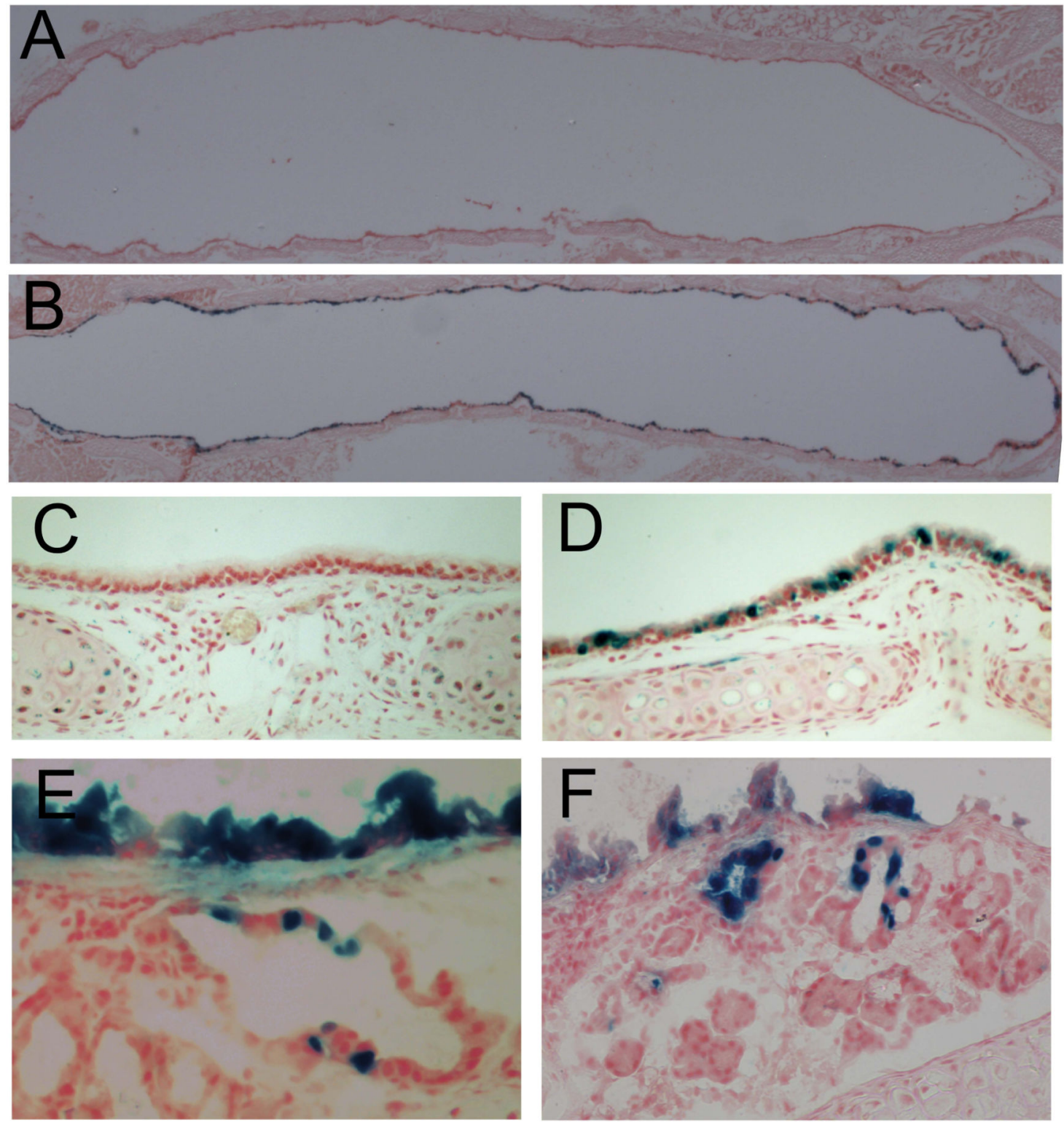

Figure 3.

Expression of influenza HA pseudotyped EIAV-CB-nlacZ vector in trachea and tracheal submucosal glands of adult mice following intranasal delivery. Three weeks following gene delivery to the right nostril of four week old CD1 (Panels A-E) or BALB/c mice (Panel F), mice were analyzed for expression of nlacZ. Panels (A) and (B) show low power (x4) magnification of $X$-Gal stained longitudinal cryosections of a non-transduced control mouse trachea and EIAV-CB-nlacZ transduced mouse trachea, respectively. Panels (C) and (D) are higher magnification (x10) histologic sections of X-Gal stained control trachea and EIAVCB-nlac transduced mouse trachea, respectively (E) X-Gal stained cryosection from proximal region of trachea from a CD1 mouse transduced with EIAV-CB-nlac. (F) X-Gal stained cryosection from proximal region of trachea from a BALB/c mouse transduced with EIAV-CB-nlac. The images in (E) and (F) show X-Gal stained cells within submucosal glands below the tracheal surface. Sections were counterstained with nuclear fast red. 

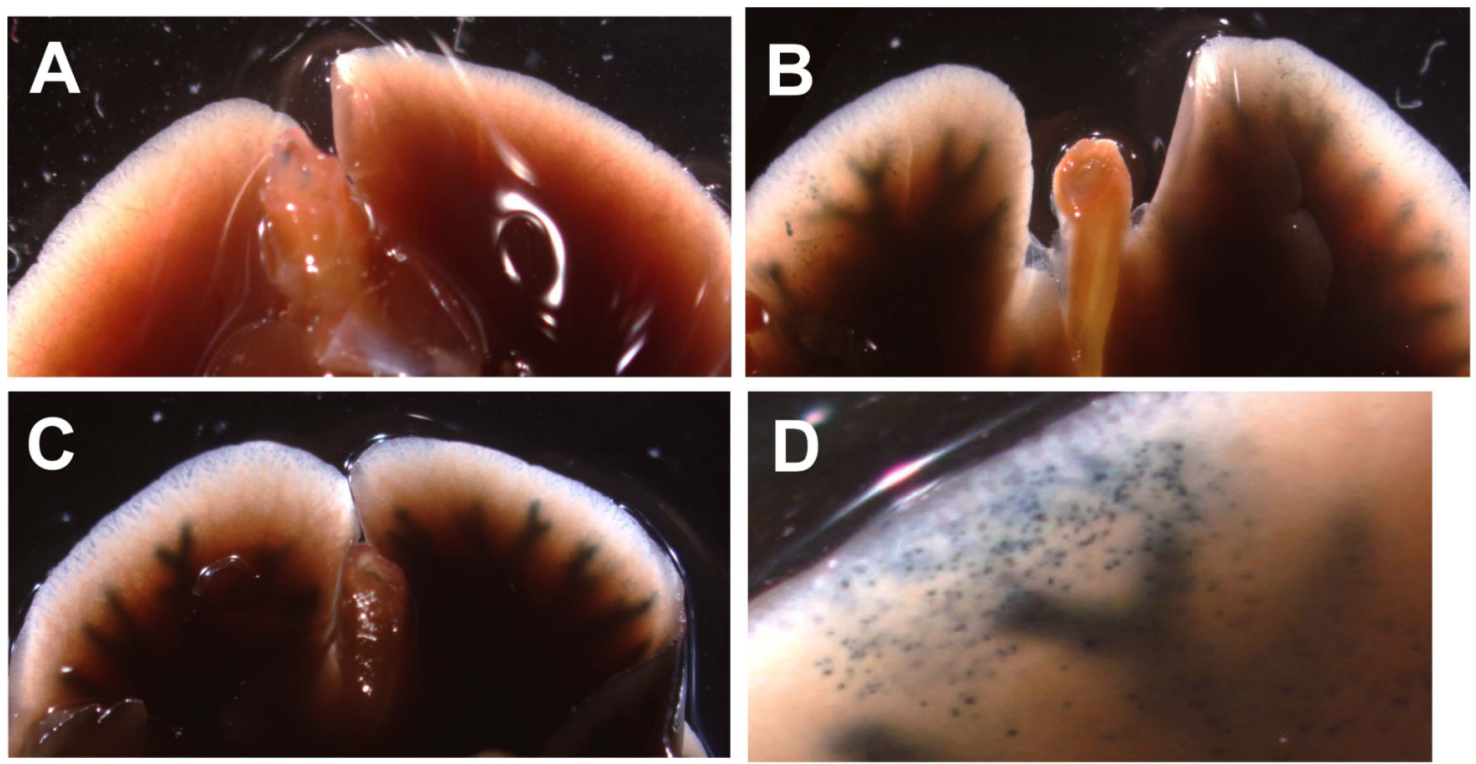

Figure 4.

Expression of influenza HA-pseudotyped EIAV-CB-nlacZ in whole mouse lung following intranasal delivery. $X-G a l$ stained whole lungs from (A) control CD1 mouse and $(B, C)$ mice dosed with HA-pseudotyped EIAV-CB-nlacZ vector. The close-up (D) of an EIAV-CB-nlacZ dosed animal indicates staining consistent with gene transfer to terminal bronchiolar regions. 

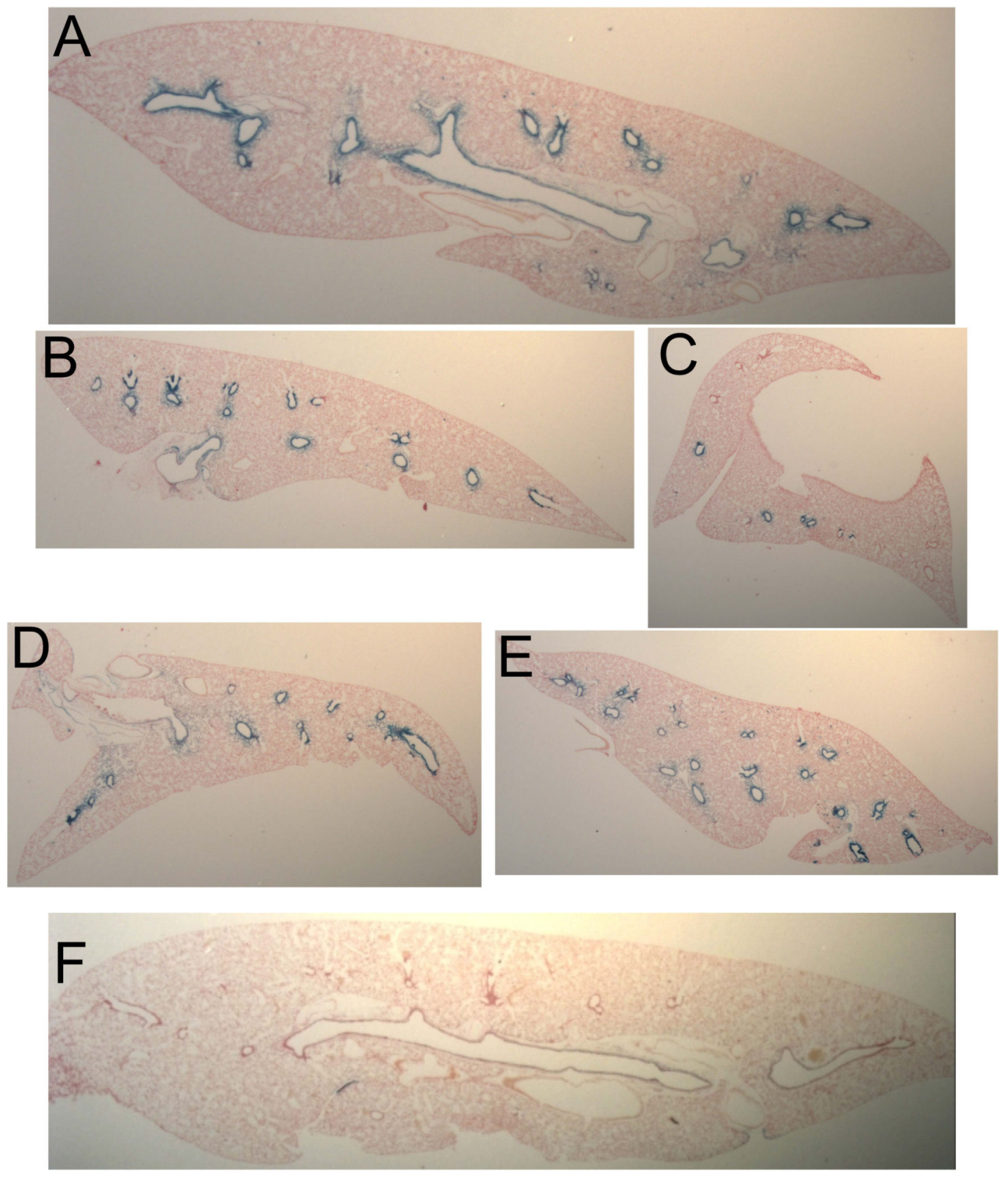

Figure 5.

Gene transfer to all lobes of mouse lung following intranasal delivery of HA-pseudotyped EIAV-CB-nlac $Z$ vector. Panels show scanned images of longitudinal sections of dissected mouse lung lobes from a single CD1 mouse counterstained with nuclear fast red. The whole lung was inflated and stained with X-Gal prior to sectioning. Mouse lobes include: (A) left lobe; (B) apical lobe; (C) azygous lobe; (D) cardiac lobe; and (E) diaphramatic lobe. Panel (F) shows the left lobe from a sham-infected control animal stained with X-Gal and counterstained with nuclear fast red (original magnification, $\mathrm{x} 4$ ). 

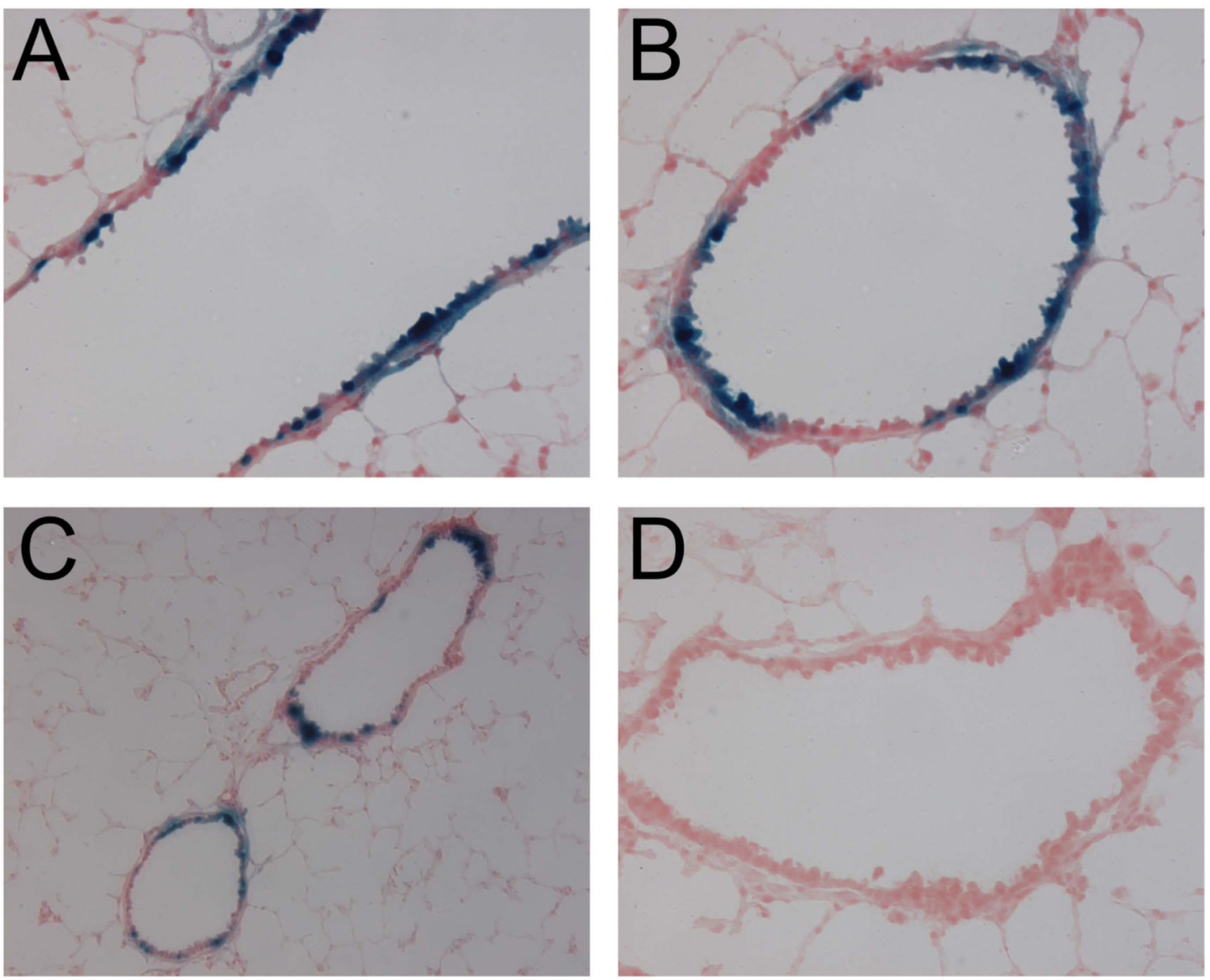

Figure 6.

$\mathrm{X}$-Gal stained cryosections from lungs of CD1 mice transduced with HA-pseudotyped lentiviral vectors encoding nlacZ. (A) Distal region of bronchi from mouse transduced with EIAV-CB-nlacZ. (B) Bronchiole from mouse transduced with EIAV-CB-nlacZ. (C) Bronchioles from CD1 mouse transduced with HIV-1 based vector LV-CB-nlacZ. The expression cassette is identical to that used in EIAV-CB-nlacZ. (D) Bronchiole from shaminfected control mouse. Original magnification (x20) except for panel C (x10). 

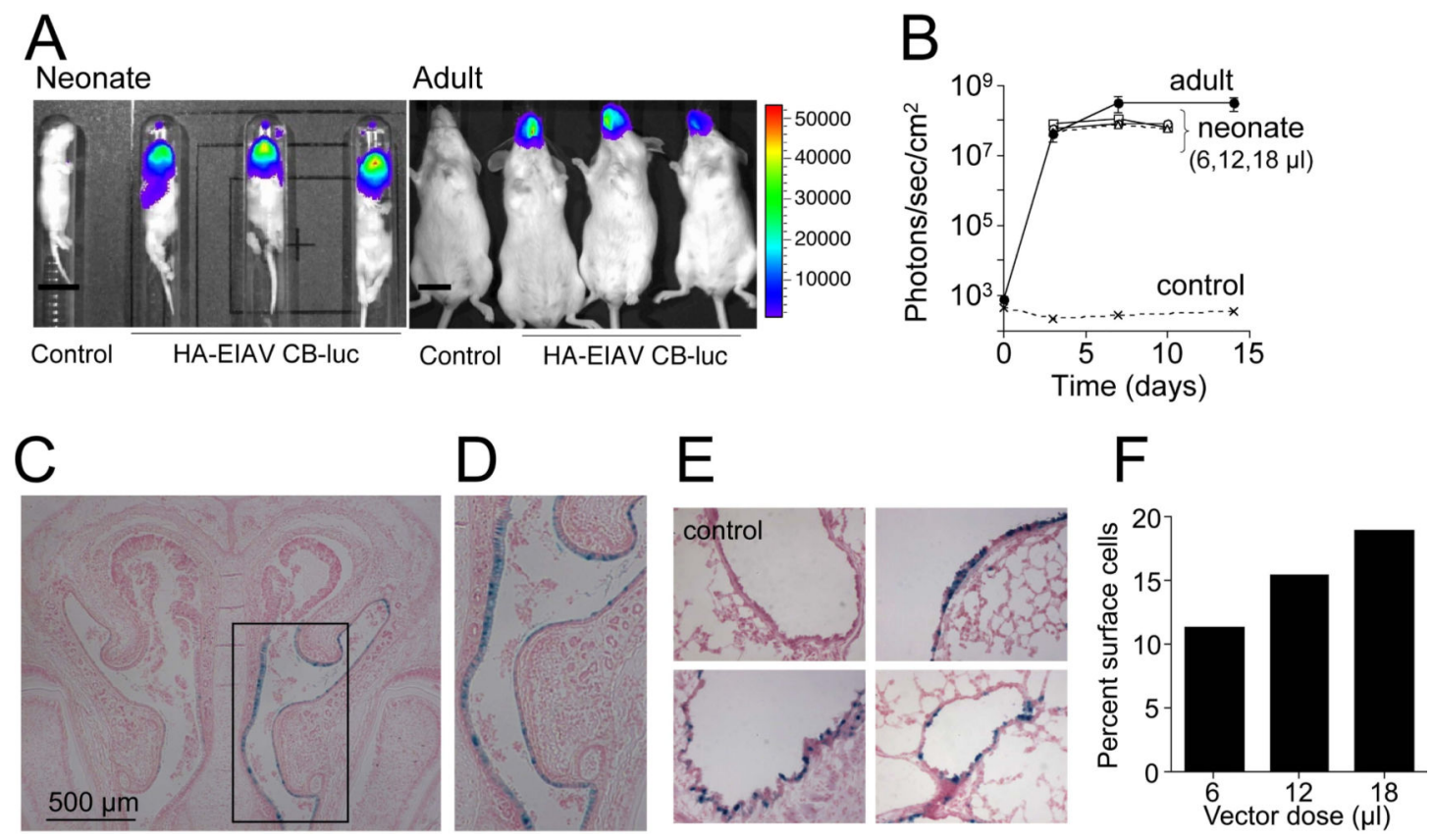

Figure 7.

Nasal delivery of influenza HA-pseudotyped EIAV-CB-nlacZ-luciferase vector to neonatal mice. (A) Luciferase imaging of young mouse pups. Three days after intranasal delivery of a dual EIAV-CB-nlacZ-luciferase vector to 1-day-old neonatal mice or young adult (4 week old) mice, luciferin was administered intranasally and luciferase catalyzed bioluminescence was captured using the Xenogen optical imaging system. Bar in lower left of each panel represents $15 \mathrm{~mm}$. (B) Kinetics of luciferase expression in the nose of neonatal and adult mice. The vector was delivered by nasal inhalation of 6,12 , or $18 \mu \mathrm{L}$ (total volume) to newborn mice (1-2 days old) or $20 \mu \mathrm{L}$ to 4 -week-old young adult mice. The titer of the vector was $2 \times 10^{8} \mathrm{IU} / \mathrm{mL}$. For adult mice, the vector was delivered as a single bolus. For neonatal mice the vector was delivered in $6 \mu \mathrm{L}$ doses, allowing the pups to recover completely between consecutive doses. At various times after gene transfer, luciferin was administered intra-nasally and the luciferase activity was measured. Non-transduced control animals were dosed with luciferin and imaged in parallel. Results are expressed as mean luciferase activity (photons/sec/cm $\left.{ }^{2}\right) \pm \operatorname{SEM}(\mathrm{n}=2$ mice per data point (neonates) or $\mathrm{n}=6$ mice per data point (adults). (C) Low power image of X-Gal stained coronal nose section counterstained with nuclear fast red. (D) Magnified boxed region from panel C. The heaviest stained region is along the surface of the nasal septum. (E) Cryosections from the left lung lobe of neonatal mouse ( $6 \mu \mathrm{L}$ dose) were fixed with glutaraldehyde and stained with X-Gal. Upper left panel shows X-Gal stained section from sham-infected control mouse. $(\mathrm{F})$ Quantification of gene transfer to neonatal lung. The percentage of X-Gal stained blue cells per total number of surface cells from the large airway in the left lung lobe was determined using image analysis. Results are expressed as mean percentage ( $\mathrm{n}=2$ mice per data point). 


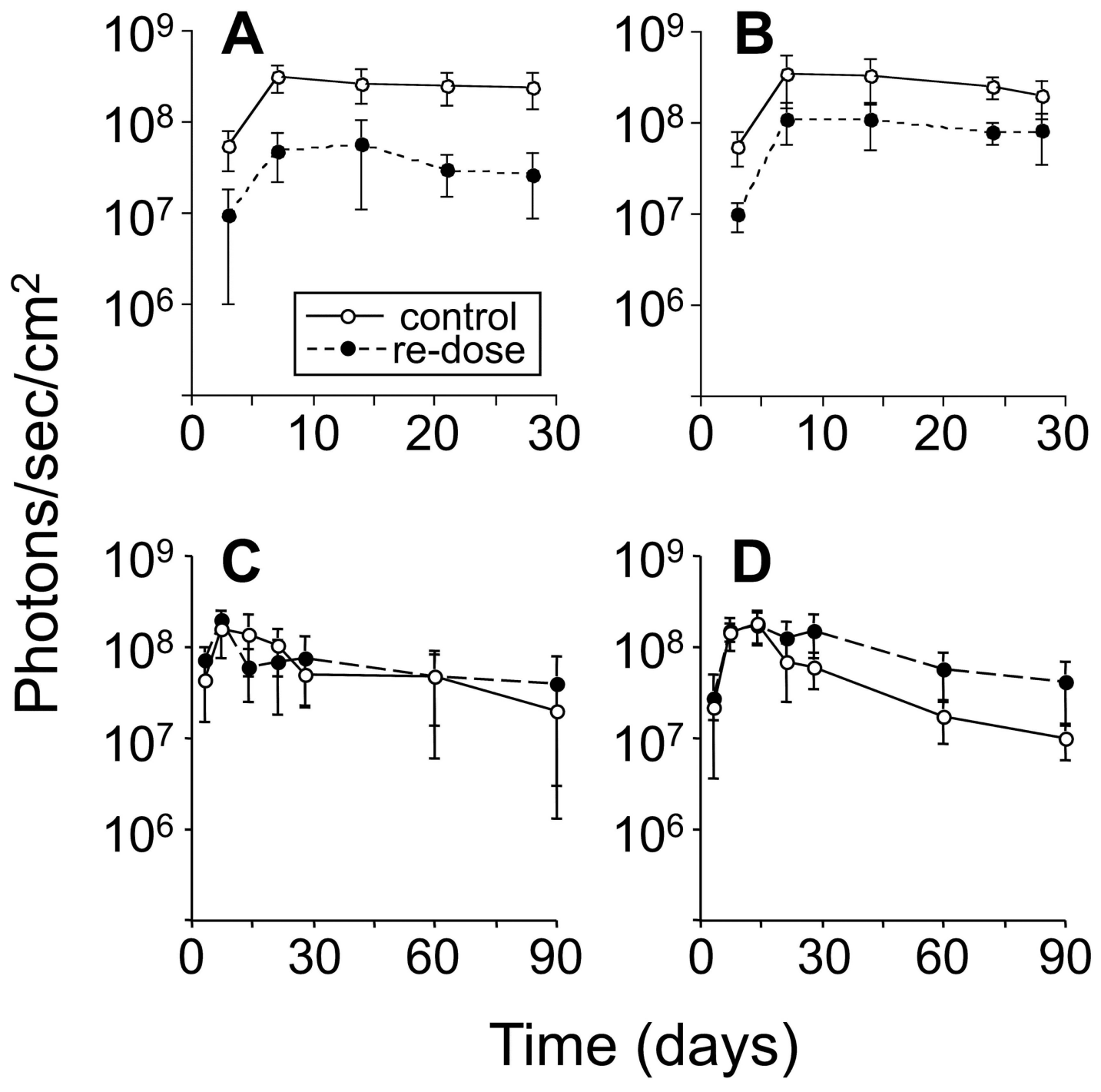

Figure 8.

Repeat administration of HA-pseudotyped EIAV vectors to nasal epithelium of mice. 'Control' mice received a single dose of EIAV-CB-luciferase $\left(7 \times 10^{6} \mathrm{IU}\right)$. 'Re-dose' mice received EIAV-CB-nlac $Z\left(2.8 \times 10^{7} \mathrm{IU}\right)$ at either four weeks of age (panels A and B) or 1-2 days after birth (panels $\mathrm{C}$ and $\mathrm{D}$ ) followed either 3 weeks (panels $\mathrm{A}$ and $\mathrm{C}$ ) or 3 months (panels B and D) later with EIAV-CB luciferase $\left(7 \times 10^{6} \mathrm{IU}\right)$. 'Control' mice and 're-dose' mice were dosed with the EIAV-CB-luciferase vector on the same day. Luciferase expression was monitored using a Xenogen CCD system after nasal luciferin administration. Each point represents the mean photons/sec/ $\mathrm{cm}^{2} \pm \mathrm{SEM}, \mathrm{n}=4$ for each group after subtracting out values from negative control mice. Negative control mice (undosed, age-matched) were imaged in parallel in each imaging session and had an average signal of less than $10^{4}$ photons $/ \mathrm{sec} / \mathrm{cm}^{2}$. 

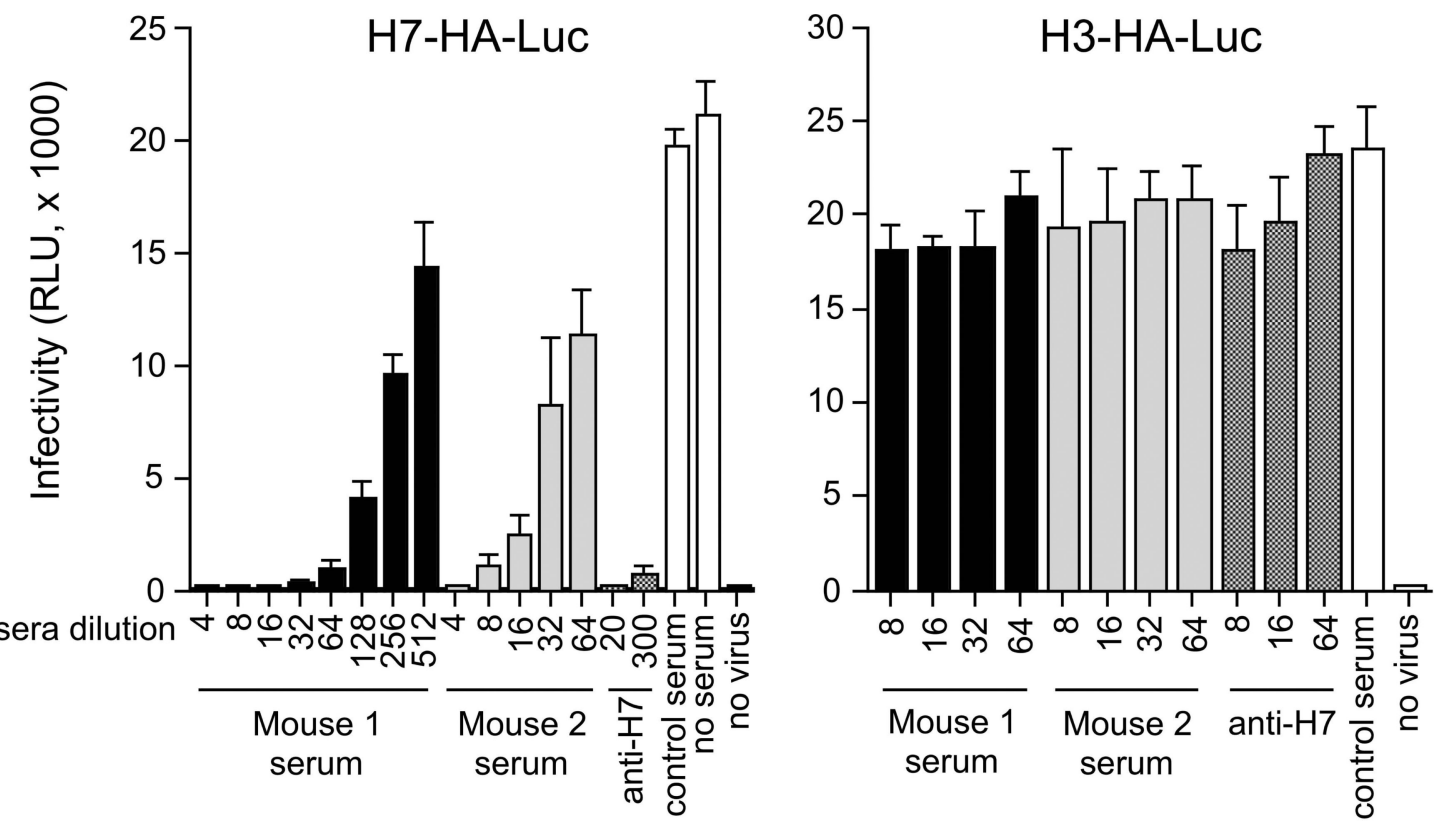

Figure 9.

Detection of influenza subtype $\mathrm{H} 7 \mathrm{HA}$-specific neutralizing activity in sera of mice transduced with influenza HA-pseudotyped EIAV-nlacZ vectors. The neutralization of infectivity of EIAV-luciferase vectors pseudotyped with influenza subtype H7 HA (left panel) or human influenza subtype H3 HA (right panel) was measured using dilutions of antisera ranging between 1:4 and 1:512. $\mathrm{H} 3$ or $\mathrm{H} 7$ pseudotypes were pre-incubated with anti-sera for $1 \mathrm{~h}$ at $37^{\circ} \mathrm{C}$ prior to transducing ED cells. At $48 \mathrm{~h}$ post infection luciferase activity was determined. Results are expressed as the mean luminescence measured in relative light units $(R L U) \pm$ standard error of one experiment run in triplicate. Source of antisera: Mouse 1 and Mouse 2, heat-inactivated sera from mice that received a single dose of EIAV-CB-nlacZ. Blood was harvested when the animals were sacrificed at 3 weeks after gene transfer; anti-H7, commercial antiserum raised in sheep to H7 influenza (NIBSC, Hertfordshire, UK); control serum, heat inactivated serum from sham-infected control mouse; no serum control, no virus cell background. 